\title{
Essential features of compacted silty sand behavior via suction- controlled triaxial testing
}

\author{
Ujwalkumar D. Patil ${ }^{1, a}$, Laureano R. Hoyos ${ }^{2}$, and Anand J. Puppala ${ }^{3}$ \\ ${ }^{1}$ Faculty Research Associate, University of Texas at Arlington, Arlington, Texas 76019, USA. \\ ${ }^{2}$ Professor, University of Texas at Arlington, Arlington, Texas 76019, USA. \\ ${ }^{3}$ Professor, University of Texas at Arlington, Arlington, Texas 76019, USA.
}

\begin{abstract}
The main intent of this work was to gain further insight into some of the limitations (and potential) of the Barcelona Basic Model (BBM) in predicting the stress-strain response of compacted unsaturated soils that are prone to post-peak strain-induced softening during suction-controlled shearing. To this aim, a comprehensive series of suction-controlled tests were conducted on statically compacted specimens of silty sand using a recently implemented, servo/suction-controlled, double-walled triaxial apparatus. The brittle and dilatant nature of the test soil, as expected, did not allow for good agreement between the experimental and BBM predicted stress-strain responses of compacted silty sand, since post-peak softening was not adequately captured. BBM simulations, however, held reasonably good during the early shearing stage (up to about $1-2 \%$ total shear strain), and at higher values of shear strain, that is, close to critical state condition.
\end{abstract}

\section{Introduction}

Despite several elasto-plastic constitutive models being proposed, the critical-based framework originally proposed by [1] remains to date; the most widely cited and used model for unsaturated soils. Soil modelers face a challenge to accommodate all possible suction ranges of unsaturated soil responses. These include post-peak softening, accompanied by stress-induced dilatancy that is exhibited typically by dense soils. Other challenges include strain-hardening type responses, accompanied by volumetric compressive behavior, which is typical of loose soils, swelling and collapse under wetting, as well as shrinkage and cracking while drying.

The verification of proposed constitutive relations must be conducted for a wide range of soils in order to ensure uniqueness and subsequent confidence on the part of researchers and practicing geotechnical engineers [4]. In the last two decades, the model has been the subject of increasingly sophisticated enhancements, mainly from a theoretical standpoint (e.g., [8], [14], [3], [2], [13], [5], [15], [11], and [6]). However, as previously mentioned, conclusive evidence of its validation for heavily consolidated materials which are distinctly brittle and dilatant in nature, particularly their post-peak softening behavior, is still lacking, mainly due to a large scarcity of experimental data of this kind. In this study, constitutive parameters postulated by the BBM framework are experimentally calibrated from the series of suction-controlled triaxial tests and then used for predicting compacted silty sand response at matric suction states from 50 to $750 \mathrm{kPa}$.

\section{Test material}

The test soil comprising of sand (55\%), silt (37\%), and clay (8\%), is classified as silty sand (SM) according to the Unified Soil Classification system (USCS). The standard proctor test resulted in maximum dry unit weight of 1.87 $\mathrm{g} / \mathrm{cm}^{3}$ and optimum moisture content of $12.2 \%$.

\section{Specimen preparation and suction- controlled triaxial system}

Each specimen was statically compacted in nine equal layers at moisture content of $14.2 \%(+2.2 \%$ wet of optimum) and target dry density of $1.8 \mathrm{~g} / \mathrm{cm}^{3}$. Each layer was compressed statically in a mold using a $50 \mathrm{KN}$ load frame at a constant rate of $1 \mathrm{~mm} / \mathrm{min}$ to a total vertical stress of $1600 \mathrm{kPa}$ to produce uniformly compacted specimens of 2.8 inch diameter and 5.6 inch height.

A photograph of automatic new double-walled triaxial equipment with frictionless automatic volume change device and flushing device assembly is illustrated in Fig. 1. The efficacy of this device to duplicate tests and its functioning has been detailed by [9] and [10]. Axis-translation technique as proposed by [7] is used to impose matric suction.

${ }^{\text {a }}$ Corresponding author: ujwalkumar.patil@mavs.uta.edu 


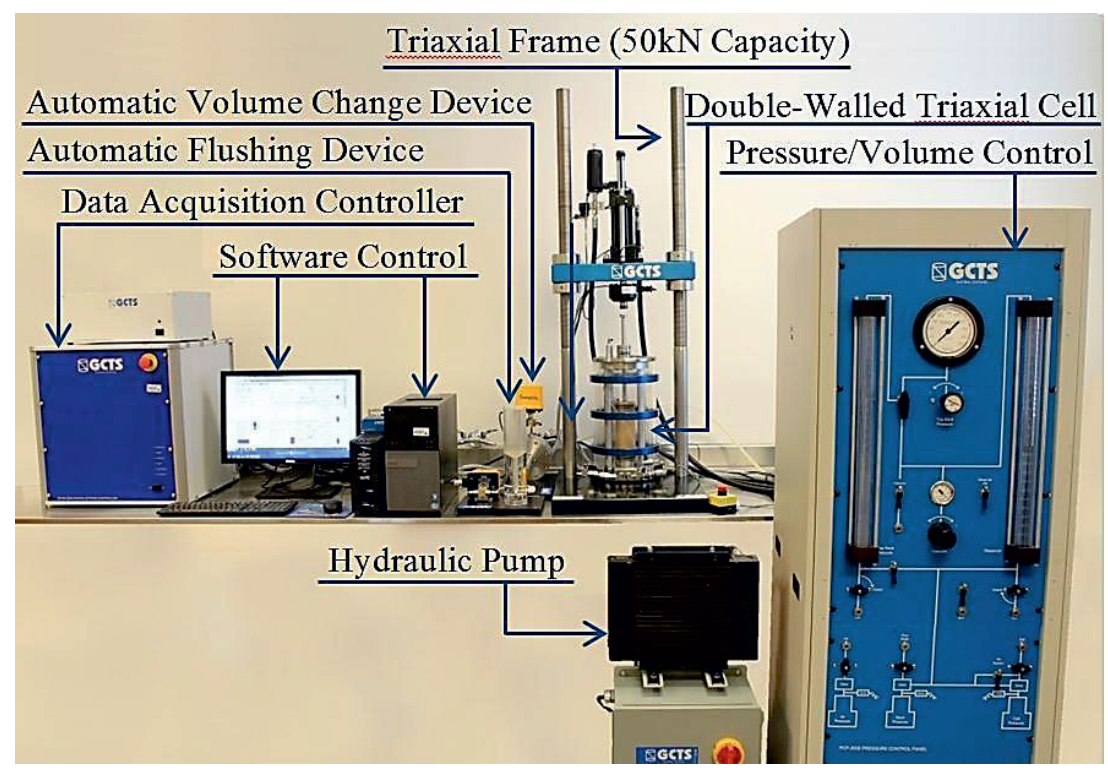

Figure 1. Servo/suction-controlled, double-walled triaxial apparatus.

\section{Calibration of BBM parameters}

[1] postulated a unified, critical state based, constitutive framework for unsaturated soils by extending the modified Cam Clay model [12], from saturated to unsaturated form, using suction as an independent stress variable, while introducing the concept of the loading-collapse (LC) yield surface.

\subsection{Calibration of BBM parameters under iso- tropic loading}

BBM postulated yield function represents an ellipseshape yield surface in $\mathrm{p}: \mathrm{q}$ plane, beyond which plastic compression occurs on account of increased stress or decreased suction. The model assumes that only elastic strains will be accumulated when the soil state lies inside a state boundary hypersurface, as given by the following:

$$
f_{1}=f(p, q, s)=q^{2}-M^{2}\left(p+p_{s}\right)\left[p_{o}(s)-p\right]=0
$$

where, $\mathrm{M}=$ slope of the critical state line in $\mathrm{p}: \mathrm{q}$ plane, and

$$
\mathrm{p}_{\mathrm{s}}=\mathrm{ks}
$$

where, $\mathrm{k}=$ slope of the apparent tensile strength locus in $\mathrm{p}$ :s plane. The model assumes a monotonic decrease of the volumetric stiffness parameter $\lambda(s)$ with increasing suction, expressed as follows:

$$
\lambda(s)=\lambda(0)\left[(1-r) e^{(-\beta s)}+r\right]
$$

where, $r=\frac{\lambda(\mathrm{s} \rightarrow \infty)}{\lambda(0)}$, and

$\beta=$ parameter controlling the rate of increase of soil stiffness with matric suction. The yield surface at constant suction may be described by an ellipse marked by an isotropic consolidation stress, $\mathrm{p}_{\mathrm{o}}(\mathrm{s})$, that lies on the loading-collapse (LC) yield curve, which in turn takes the following form in p:s plane:

$$
\frac{p_{o}(s)}{p^{c}}=\left[\frac{p_{o}(0)}{p^{c}}\right]^{\frac{\lambda(0)-\kappa}{\lambda(s)-\kappa}}
$$

where, $p_{o}(s)=$ yield stress that varies with matric suction; $p_{o}(0)=$ preconsolidation stress under saturated condition; $\mathrm{p}^{\mathrm{c}}=$ reference preconsolidation stress at which the LC locus becomes a straight line, i.e., $p_{0}(s)=p^{c} ; \lambda(0)=$ compressibility coefficient for saturated state along virgin loading; $\lambda(s)=$ soil stiffness parameter that varies with matric suction; $\kappa=$ elastic rebound index with respect to net mean stress. A non-associative flow rule (Eqn. 5) was adopted for the direction of plastic shear strain increments $d \varepsilon^{p}{ }_{q}$ and is given as:

$$
d \varepsilon_{q}^{p}=\frac{2 \alpha q_{C}}{M^{2}\left[2 p_{C}+p_{s}-p_{o}^{C}(s)\right]} d \varepsilon_{v p}^{p}
$$

where the constant $\alpha$ is defined as follows:

$$
\alpha=\frac{M(M-9)(M-3)}{9(6-M)}\left[\frac{1}{1-\frac{\kappa}{\lambda(0)}}\right]
$$

The least square method was used to solve the overdetermined system in Equation (3), allowing for the determination of constitutive parameters $\lambda(0), r$, and $\beta$. Using experimental values, $\lambda(50)=0.01381, \lambda(250)=$ $0.012146, \lambda(500)=0.005097$, and $\lambda(750)=0.0061339$, 
best-fit values for these three unknowns were found to be $\lambda(0)=0.02, \mathrm{r}=0.26$, and $\beta=2.0 \mathrm{MPa}^{-1}$, with a coefficient of determination, $\mathrm{R}^{2}=0.85$. Figures 2 show the experimentally calibrated values of the stiffness parameter $\lambda(s)$, along with its parametric predictions, using Eq. (3), for different values of parameters $\beta$. Reasonably good agreement is observed between experimental and predicted values of volumetric stiffness $\lambda(s)$ for this partial set of calibrated parameters.

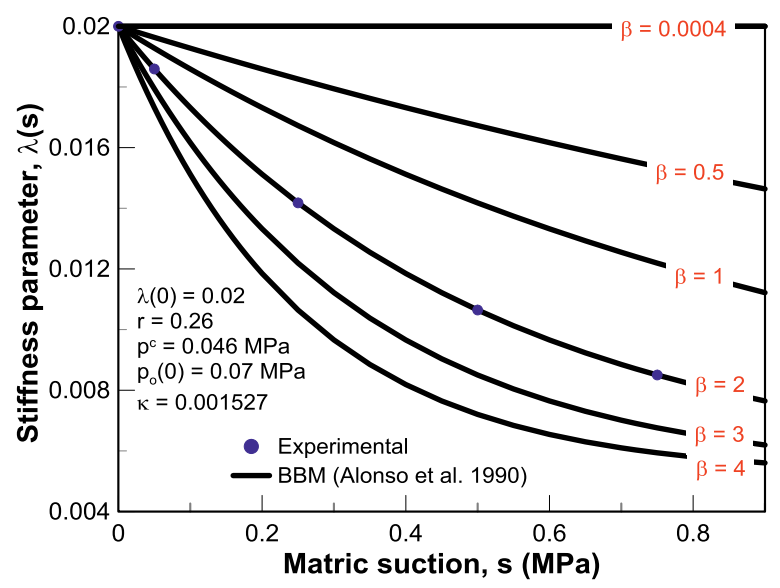

Figure 2. Experimental stiffness parameter, $\lambda(s)$ for test soil and predicted curves for various values of $\beta$ using Equation (3).

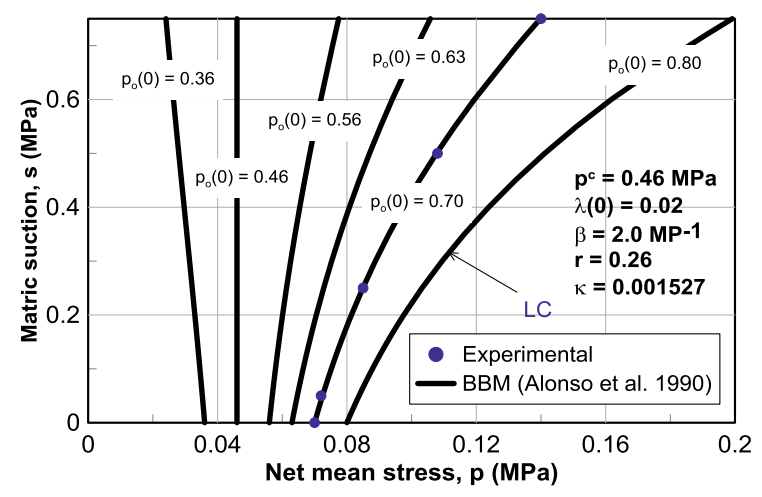

Figure 3. Experimental yield stress values on best-fit LC curve and typical curves predicted for different values of $p_{0}(0)$.

The same method is used to solve the overdetermined system in Eq. (4), thus allowing for the assessment of parameters $\mathrm{p}^{\mathrm{c}}$ and $\mathrm{p}_{\mathrm{o}}(0)$. Using experimental values, $\mathrm{p}_{\mathrm{o}}(50)=72 \mathrm{kPa}, \mathrm{p}_{\mathrm{o}}(250)=83 \mathrm{kPa}, \mathrm{p}_{\mathrm{o}}(500)=120 \mathrm{kPa}$, and $\mathrm{p}_{\mathrm{o}}(750)=140 \mathrm{kPa}$, best-fit values for these two unknowns were found to be $\mathrm{p}^{\mathrm{c}}=46 \mathrm{kPa}$, and $\mathrm{p}_{\mathrm{o}}(0)=70$ $\mathrm{kPa}$, with a coefficient of determination, $\mathrm{R}^{2}=0.99$.

The experimental data points from compacted silty sand used in this research show a very close agreement with the LC curve predicted for $p_{o}(0)=70 \mathrm{kPa}$. The figure also illustrates the reference preconsolidation stress, for which the LC curve becomes a perfectly straight line, calibrated to a value equal to $46 \mathrm{kPa}$.

\subsection{Calibration of BBM parameters under ax- isymmetric shearing}

Figure 4 shows the best-fit critical state lines (CSLs) obtained from the series of suction-controlled CTC tests, as plotted in p:q:s space, for matric suction values, $\mathrm{s}=0$, $50,250,500$, and $750 \mathrm{kPa}$. It can be observed that the slope $\mathrm{M}(\mathrm{s})$ of the CSLs remains virtually constant regardless of the level of induced matric suction, in close agreement with the original BBM formulation. This, therefore, establishes a unique relationship between deviatoric and net mean stresses for suction-controlled CD triaxial tests on compacted silty sand.

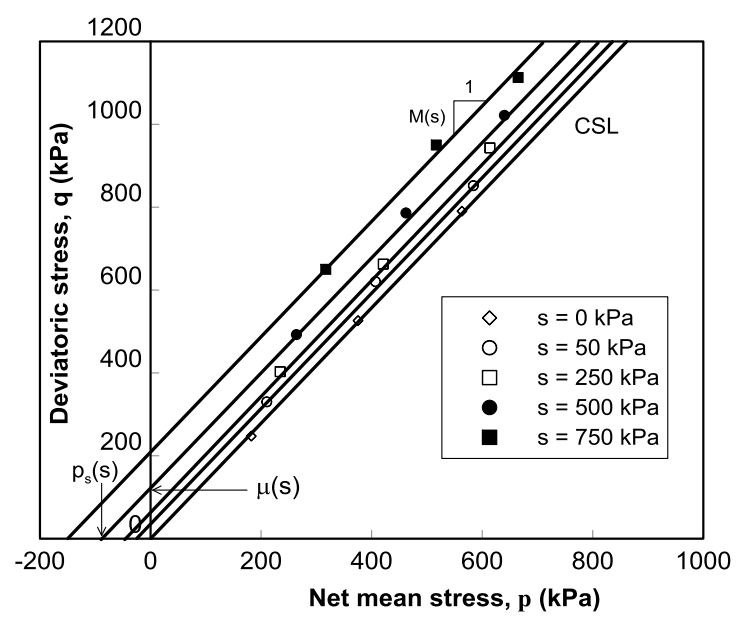

Figure 4. Critical state lines in $\mathrm{p}-\mathrm{q}$ plane generated from suction-controlled $\mathrm{CD}$ triaxial tests via axis-translation.

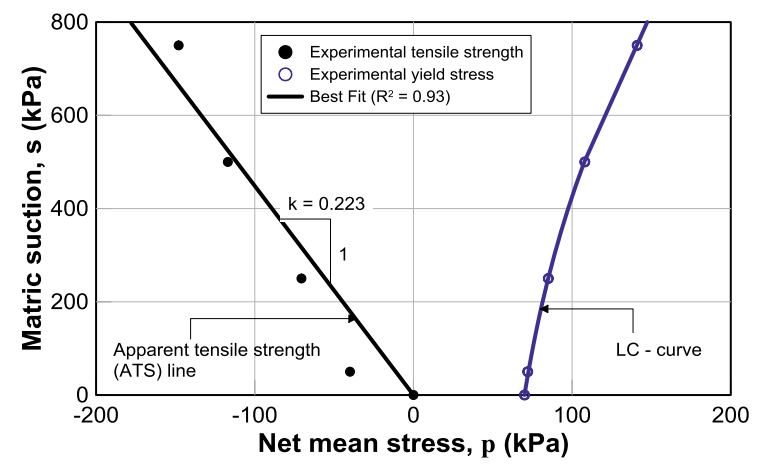

Figure 5. Apparent tensile strength (ATS) and loading-collapse (LC) loci experimentally assessed from suction-controlled isotropic loading.

It can be readily noticed from Figure 4 that the slope of the critical state lines remains virtually constant despite the introduction of suction. Thus, it establishes a unique relationship between deviator and net mean stresses for suction-controlled CD triaxial tests. However, a noticeable upward shift in the position of critical state line is observed with the introduction of matric suction, as compared to its saturated counterpart. The intersection of the CSLs with the q-axis gives the magnitude of the apparent cohesion, $\mu(\mathrm{s})$; while the intersection of the CSLs with the negative p-axis gives the magnitude of the additional tensile strength, $\mathrm{p}_{\mathrm{s}}(\mathrm{s})$, offered by the soil with increasing matric suction. 
Additional constitutive parameters postulated by the BBM framework, including the slope of the apparent tensile strength (ATS) locus in p:s plane, and the slope of the CSLs, as defined by Eqs. (1) and (2), can now be experimentally calibrated. Figure 5 shows the LC yield curve assessed for compacted silty sand from suctioncontrolled isotropic consolidation tests, along with the ATS locus assessed in p:s plane from the best-fitted CSLs obtained from suction-controlled CTC tests. Within the range of stresses applied in this work, i.e., matric suction, $\mathrm{s}=50$ to $750 \mathrm{kPa}$, and initial net mean stress, $\mathrm{p}=\left(\sigma_{3}-\mathrm{u}_{\mathrm{a}}\right)$ $=100$ to $300 \mathrm{kPa}$, a three-dimensional plain surface plane, as given by Eq. (7), can be used to best-fit all of the experimental values of deviatoric stress at critical state:

$$
\mathrm{q}=\mathrm{Mp}+\mathrm{Mks}=1.42 \mathrm{p}+0.316 \mathrm{~s}
$$

The plane yields best-fit values, $\mathrm{M}=1.42$, for the slope of CSLs and, $\mathrm{k}=0.223$, for the rate of increase in ATS with suction. Predicted values of deviator stress are reasonably close to those experimentally obtained from suction-controlled CTC tests, yielding a coefficient of determination, $\mathrm{R}^{2}=0.93$, as shown in Figure 5 .

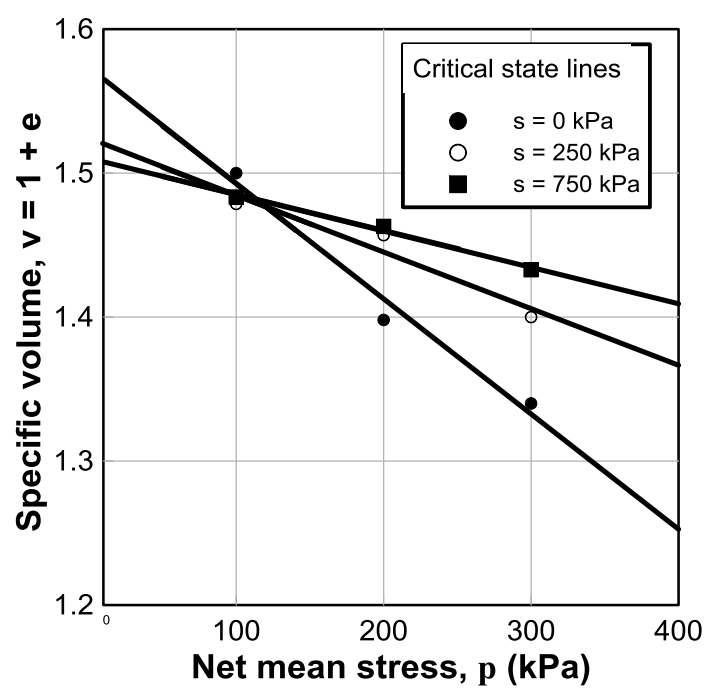

Figure 6. Critical state lines at failure in $p-v$ plane.

As a consequence of the non-associative flow rule postulated by the BBM through Equations (5) and (6), no plastic shear strain is expected to occur during initial shearing when the soil is under lightly overconsolidated condition. Hence, the elastic shear modulus can be estimated from the initial portion of the deviator stress vs. total shear strain response, which yields an average value, $\mathrm{G}=25 \mathrm{MPa}$, for the compacted silty sand tested in this work.

Post-consolidation states under isotropic loading are assumed to follow a normal consolidation line (NCL) in v:p plane. However, as the soil gets sheared, the soil state moves from its initial position on the NCL, eventually reaching a CSL. All the unsaturated specimens showed initial contraction followed by significant dilation, modulated by the level of induced matric suction, just as the volume change paths in p:v plane, where the slope of the CSL is observed to decrease with increasing suction, as postulated by the BBM.

Figure 6 shows the experimentally assessed CSLs in $\mathrm{p}: \mathrm{v}$ plane for matric suction values, $\mathrm{s}=0,250$, and 750 $\mathrm{kPa}$.

\subsection{BBM predictions of soil response}

The type of test performed in this research followed the conventional triaxial compression (CTC) stress path. The soil specimen was subjected to constant matric suction and to constant confining net mean pressure, $\mathrm{p}_{\text {ini }}$. The specimen failed by monotonic increase of the net axial pressure, $\sigma_{1}$, while keeping the isotropic confining pressure, $\left(\sigma_{3}-u_{a}\right)$, constant. Therefore, the stress path followed by the stress state in $p-q$ space had a slope of $1 \mathrm{H}: 3 \mathrm{~V}$. Explicit integration of key constitutive relationships has been used in this work to simulate soil response through BBM predictions of a drained (constant-s) conventional triaxial compression (CTC) test.

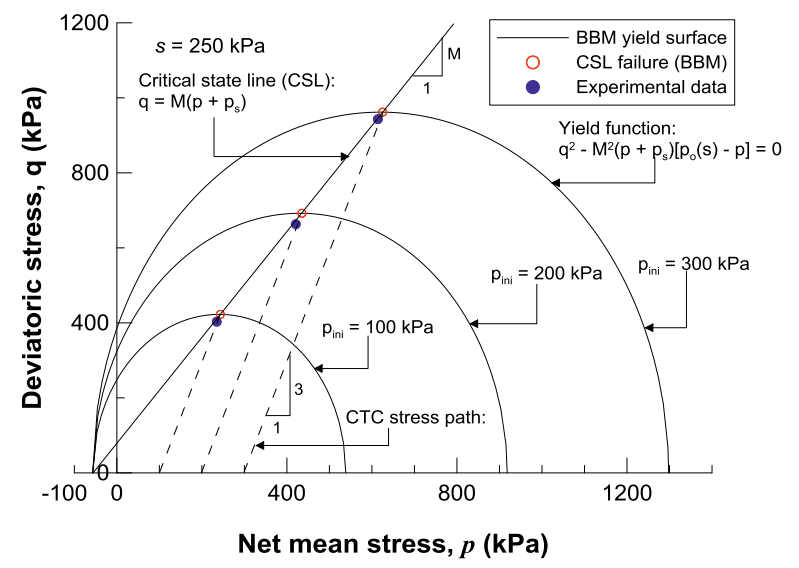

Figure 7. BBM prediction of yield surface for drained CTC tests conducted at constant matric suction, $\mathrm{s}=250 \mathrm{kPa}$, and initial net mean stresses, $p_{\text {ini }}=100,200$, and $300 \mathrm{kPa}$.

For hardening materials, continued shearing along a suction-controlled CTC stress path (Fig. 7) is expected to cause the elliptical yield surface in p:q plane to move outward (or increase in size) from the current point, while it would move inward (or shrink in size) for softening materials. The relative position of the current stress state with respect to the CSL governs whether the material sustains plastic dilatancy or contractancy.

Figures 8 and 9 show comparisons between BBM predicted and experimental deviator stress vs. shear strain response of compacted silty sand from fully drained (constant suction) CTC tests conducted at two different values of matric suction, $\mathrm{s}=250 \mathrm{kPa}$ and $500 \mathrm{kPa}$, and for initial value of net mean stress, $\mathrm{p}=\left(\sigma_{3}-\mathrm{u}_{\mathrm{a}}\right)=100 \mathrm{kPa}$ and 300 $\mathrm{kPa}$, respectively. In general, no close agreement is observed between the experimental and predicted soil responses, primarily given the largely brittle and dilatant nature of the test soil before it reaches critical state.

The original BBM framework, however, does not contemplate a stress state that fails to overcome the CSL dur- 
ing plastic loading, since the peak stress is always assumed to be reached at critical state. Therefore, it is not expected to be suitable for reproducing the transition from initial contractancy to dilatancy, and hence the postpeak strain-softening commonly observed in dense or overconsolidated geomaterials (Figs. 8-9).

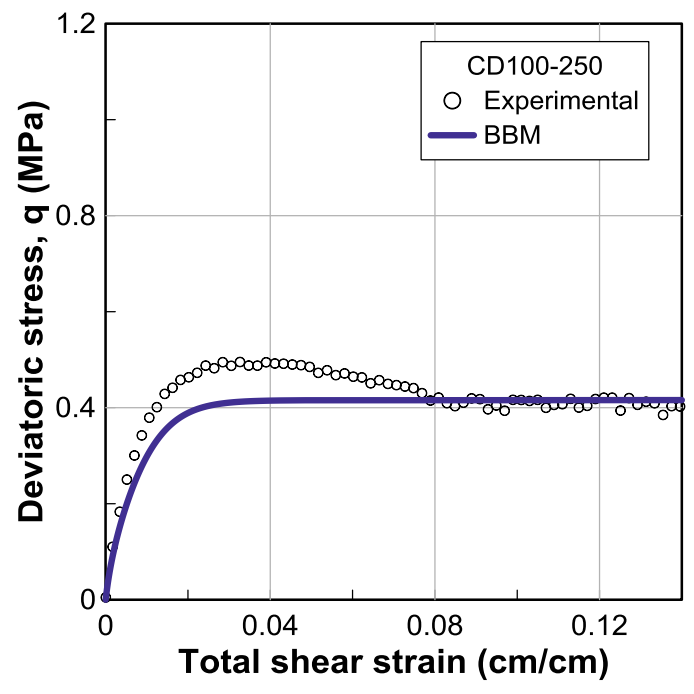

Figure 8. Experimental and BBM predicted response of silty sand from triaxial test CD100-250.

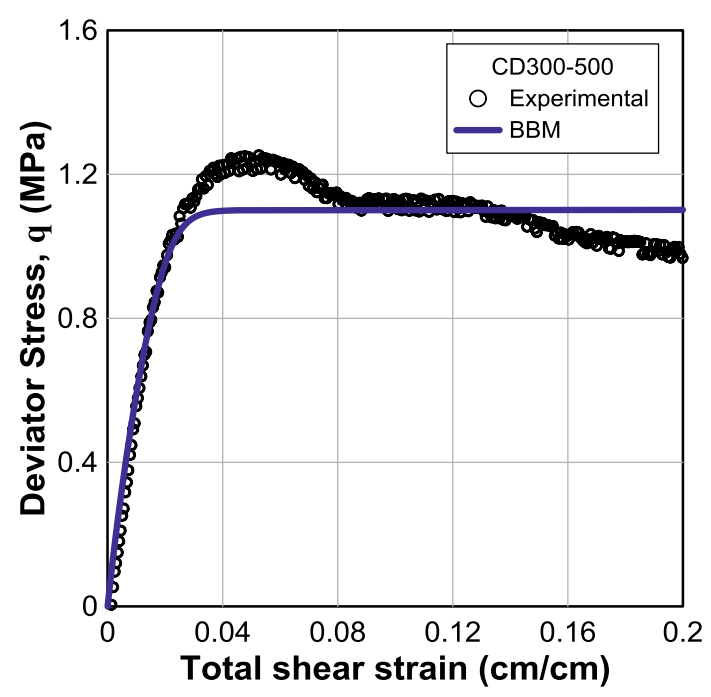

Figure 9. Experimental and BBM predicted response of silty sand from triaxial test CD300-500.

In effect, although predictions of deviatoric stress at critical state (end values) proved to be reasonably close to those experimentally observed (Fig. 8 and 9), BBM predictions considerably deviate from the stress-strain response of compacted silty sand, particularly at higher matric suctions and net confining pressures, which are precisely the stress state for which the test soil exhibits largest post-peak softening, accompanied by significant dilation.

From a qualitative standpoint, however, reasonably good predictions are generally observed for most of the initial shearing stage, up to about $1-2 \%$ shear strain, and at considerably large values of shear strain, i.e., critical state. As previously stated, these results are valuable to unsaturated soil constitutive modelers in validating more suitable frameworks for compacted or overconsolidated intermediate geomaterials when subjected to suctioncontrolled monotonic shearing.

\section{Concluding remarks}

BBM predictions of continuous stress-strain response of compacted silty sand were made by using the experimentally calibrated parameters, and compared with experimental results. Numerical predictions were implemented by using the explicit integration technique.

Given the evidently "brittle" and "dilatant" nature of the test soil, no good agreement was observed between the experimental and BBM predicted stress-strain responses. The post-peak softening of the test soil was not adequately captured. BBM simulations, however, hold reasonably good mostly during the early shearing stage, up to about $1-2 \%$ shear strain, and at higher values of shear strain (i.e. at critical state).

\section{Acknowledgements}

The experimental work described in this paper is part of an ongoing research project funded by National Science Foundation (NSF-MRI award ID \# 1039956). This support is gratefully acknowledged. Any findings, conclusions, or recommendations expressed in this material are those of the authors and do not necessarily reflect the views of the National Science Foundation.

\section{References}

1. Alonso, E.E., Gens, A., and Josa, A. "A constitutive model for partially saturated soils." Géotechnique, 40 (3), 405-530, (1990).

2. Bolzon, G., Schrefler, B. A. and Zienkiewicz, O. C. "Elastoplastic soil constitutive laws generalized to partially saturated states." Géotechnique, 46 (2), 279 289, (1996).

3. Cui, Y.J., and Delage, P. "Yielding and plastic behavior of an unsaturated compacted silt." Géotechnique, 46(2), 291-311, (1996).

4. Fredlund, D. G., and Rahardjo, H. "Soil mechanics for unsaturated soils." New York, Wiley, (2012).

5. Georgiadis, K., Potts, D. M., and Zdravkovic, L. "Three-dimensional constitutive model for partially and fully saturated soils." International Journal of Geomechanics, 5 (3), 244-255, (2005).

6. Hoyos, L. R., Diego D. Perez-Ruiz and Puppala, A.J. "Modeling unsaturated soil response under suctioncontrolled true triaxial stress paths." International Journal of Geomechanics, ASCE. 12 (3), 292-308, (2012).

7. Hilf, J. W. "An investigation of pore water pressures in compacted cohesive soils." U.S. Dept. of the interior, Bureau of Reclamation, Tech. Mem. 654, Denver, Col., U.S.A (1956). 
8. Josa, A., Balmaceda, A., Gens, A., and Alonso, E. E. "An elastoplastic model for partially saturated soils exhibiting a maximum of collapse." Proceedings, $3^{\text {rd }}$ International Conference on Computational Plasticity, Barcelona, 1, 815-826 (1992).

9. Patil, U. D., Puppala, A. J., and Hoyos, L. R. (2014). "Strength/volume change behavior of compacted silty sand using a novel double-walled suctioncontrolled triaxial system." Unsaturated Soils: Research and Applications - Proceedings of the $6^{\text {th }}$ International conference on unsaturated soils, UNSAT 2014, 2, 1727-1733 (2014).

10. Patil, U. D. "Response of unsaturated silty sand over a wider range of suction states using a novel doublewalled triaxial testing system." Ph.D. dissertation, Univ. of Texas at Arlington, Arlington, TX, USA (2014).

11. Russel, A. R. and Khalili, N. "A unified bounding surface plasticity model for unsaturated." International Journal of Numerical and analytical methods in Geomechanics, 30 (3), 181-212 (2006).

12. Schofield, A., and Wroth, C. P. "Critical state soil mechanics." McGraw-Hill, London (1968).

13. Vaunat, J, Romero, E., and Jommi, C. "An elastoplastic hydro-mechanical model for unsaturated soils." Experimental evidence and theoretic approaches in unsaturated soils (Eds. Tarantino, A. and Mancuso, C ), 121-138, Rotterdam: Balkema, (2000).

14. Wheeler, S. J., and Sivakumar, V. "An elasto plastic critical state framework for unsaturated soil." Géotechnique, 45 (1), 35-53 (1995).

15. Yu, H. S. "Plasticity and geotechnics." Springer, New York, (2006). 